\title{
CARACTERIZAÇÃO DE ALFA-GALACTOSIDASE EM EMBRIÃO E COTILÉDONES DE SEMENTES DE Platymiscium pubescens MICHELI, VAR. PUBECENS (TAMBORIL-DA- MATA)'.
}

\author{
EDUARDO EUCLYDESDE LIMA², SEBASTIÃO TAVARESDE REZENDE ${ }^{3}$, \\ RITADE CASSIAGONÇALVES BORGES ${ }^{2}$, SONIACRISTINAJ. G.A. PEREZ ${ }^{4}$
}

\begin{abstract}
RESUMO - Sementes de Platymiscium pubescens foram colocadas para embeber em água, sendo retiradas amostras para as caracterizações bioquímica e cinética da enzima alfa-galactosidase do eixo embrionário e dos cotilédones. A atividade específica no eixo embrionário aumenta de zero até o tempo de 96 horas de embebição, estabilizando em seguida. A atividade da enzima dos cotilédones mostrou pequeno incremento durante esse mesmo tempo. A alfa-galactosidase do eixo embrionário apresentou atividade máxima no intervalo de $\mathrm{pH}$ de 4,5 a 6,0. Por outro lado, para a enzima proveniente dos cotilédones, a maior atividade foi detectada na faixa de 4,0 a 6,0 . A temperatura de $55^{\circ} \mathrm{C}$ foi a que mais estimulou as atividades da alfa-galactosidase do eixo embrionário e dos cotilédones. As enzimas do eixo embrionário e dos cotilédones mostraram-se termotolerantes, não se alcançando a meia vida na temperatura de $40^{\circ} \mathrm{C}$, no período de 1.500 minutos. A atividade da alfa-galactosidase do eixo embrionário foi inibida por melibiose, $\mathrm{CuSO}_{4}$ e $\mathrm{SDS}$, enquanto a dos cotilédones foi por todos os efetores, exceto com SDS, $\mathrm{CuSO}_{4}$ e galactose que tiveram efeito neutro sobre a atividade da alfa-galactosidase dos cotilédones. Os valores de $\mathrm{K}_{\mathrm{M}}$ para as alfa-galactosidases do embrião e para o cotilédone foram 3,37 e $0,26 \mathrm{mM}$, respectivamente.
\end{abstract}

Termos para indexação: espécie florestal, alfa-galactosidase, enzima.

\section{CARACTERIZATION OF ALFA-GALACTOSIDASE IN EMBRYONICAXIS AND COTYLEDONS OF Platymiscium pubescens SEEDS}

\begin{abstract}
Platymiscium pubescens seeds were placed to soak in water and sampled for biochemistry and kinetic characterizations of embryonic axis and the alfa-galactosidase cotyledon enzyme. The specific activity in the embryonic axis increased from zero to 96 hours of imbibition, stabilizing soon after. The activity of the cotyledon enzyme showed a small increase in the same period. The alfa-galactosidase of the embryonic axis presented its maximum activity in the interval of $\mathrm{pH} 4.5$ to 6.0. On the other hand, for the cotyledon enzyme, the highest activity was detected in the interval of 4.0 to 6.0 . The temperature of $55^{\circ} \mathrm{C}$ was best to stimulate embryonic axis and cotyledon alfa-galactosidase acticvity. Enzymes of the embryonic axis and the cotyledons were heat tolerant, not reaching the half life at $40^{\circ} \mathrm{C}$, in 1.500 minutes. The embryonic axis alfa-galactosidase activity was inhibited by melibiose, $\mathrm{CuSO}_{4}$ and SDS, while that of cotyledons was for all the effectors, except for SDS, $\mathrm{CuSO}_{4}$ and galactose which had neutral effect. The values of $\mathrm{K}_{\mathrm{M}}$ for the embryo and for the cotyledon alfa-galactosidases were 3.37 and $0.26 \mathrm{mM}$, respectively.
\end{abstract}

Index terms: forest specie, alfa-galactosidase, enzyme.

\footnotetext{
${ }^{1}$ Submetido em 21/10/2003. Aceito para publicação em 16/06/2004.

${ }^{2}$ Departamento de Engenharia Florestal, Universidade Federal de Viçosa, 36571-000, Viçosa, MG;
}

\footnotetext{
${ }^{3}$ Departamento de Bioquímica e Biologia Celular, Universidade Federal de Viçosa, 36571-000, Viçosa, MG;

${ }^{4}$ Departamento de Botânica, Universidade Federal de São Carlos, 13565905, São Carlos, SP.
} 


\section{INTRODUÇÃO}

A mobilização de reservas em sementes é importante passo na disponibilização de substrato para manutenção do crescimento de plântulas. Segundo Dey (1981), a rafinose é armazenada nos órgãos de reserva, sendo utilizada como precursora para a síntese de outros oligossacarídeos ou podendo ser hidrolisada por alfa-galactosidases. Camacho et al. (1992) observaram a redução de oligossacarídeos em sementes germinadas de várias espécies, redução esta explicada pelo aumento na atividade de alfa-galactosidase.

Segundo Feurtado et al. (2001), a enzima alfagalactosidase está presente no endosperma e no embrião de sementes de Lycopersicon esculentum durante e após a germinação. Ainda segundo os autores, ela se encontra em sementes secas e mantêm a atividade naquelas sementes cuja germinação foi bloqueada. A alfa-galactosidase está presente em sementes germinadas de Tachigalia multijuga (Fialho et al., 2002 a), em sementes de Platymiscium pubescens (Oliveira et al., 2002), em bactéria Cladosporium cladosporoides onde promove a liberação de galactose dos oligossacarídeos da família rafinose (Cruz et al., 1981), no caule de Colocasia esculenta (Chen \& Lin-Chu, 1991) e em raiz de Verbascum thapsus (Bom et al., 1998).

Segundo Oliveira et al. (2002), a enzima se apresenta em três isoformas em sementes de Platymiscium pubescens. Feurtado et al. (2001) também encontraram três isoformas em sementes de Lycopersicon esculentum. Fialho et al. (2002a) investigando a presença de alfa-galactosidase em sementes de diversas leguminosas concluíram que a atividade da enzima em Platymiscium pubescens foi de $0,93 \mathrm{U} / \mathrm{mL}$ e $0,73 \mathrm{U} / \mathrm{mL}$ em extrato de Tachigalia multijuga.

Segundo Borges et al. (2002) embriões de sementes de Platymiscium pubescens apresentaram diferenças significativas na atividade de alfa-galactosidase em 120 horas de embebição, muito embora não se observassem alterações significativas no teor de galactose nas frações pécticas e hemicelulósicas da parede celular no mesmo período. Dessa forma, a atividade dessa enzima nessas sementes estaria ligada à degradação de reservas de estaquiose, cuja concentração decresceu a partir de 96 horas, e rafinose, cuja presença não foi detectada em 120 horas de embebição.

Tendo em vista que os conhecimentos da presença e da atividade da alfa-galactosidase são bastante conhecidos em sementes da espécie em estudo, o objetivo da presente investigação foi de aprofundar a pesquisa a respeito da enzima em compartimentos das sementes de Platymiscium pubescens, tendo em vista a importância da mobilização de carboidratos durante a germinação de sementes.

\section{MATERIALE MÉTODOS}

Esse trabalho foi realizado no Laboratório de Análise de Sementes Florestais (LASF) do Departamento de Engenharia Florestal da Universidade Federal de Viçosa. Sementes de Platymiscium pubescens Micheli, var. pubecens, foram colocadas sobre duas folhas de papel Germitest embebidas com água, colocadas em placa de Petri, em temperatura de $30^{\circ} \mathrm{C}$, no escuro, pelo período de 120 horas. Foram utilizadas cinco repetições contendo 20 sementes cada uma delas. Diariamente foram retiradas amostras, quando as sementes foram dissecadas em cotilédones e eixo embrionário. Determinaram-se os teores de água e de proteína e quantificouse a atividade da enzima alfa-galactosidase de ambos compartimentos da semente. A extração e quantificação da atividade da enzima foram feitas segundo metodologia descrita por Viana (2002a). Para tanto, foram tomados 10 eixos embrionários ou cinco cotilédones, em cada uma das cinco repetições, e macerados separadamente em gral de porcelana com 1,0 e 2,0 mL, respectivamente, de tampão acetato de sódio $100 \mathrm{mM} \mathrm{pH} \mathrm{5,0} \mathrm{e} \mathrm{centrifugadas} \mathrm{a} 24.000 \mathrm{x}$ g por 30 min, a $4^{\circ} \mathrm{C}$. O sobrenadante foi usado para quantificação da atividade da enzima e para determinação do teor de proteína.

Foi utilizado para-nitrofenil-a-D-galactopiranosídeo ( $\rho$ NPGal) como substrato na avaliação da atividade da alfagalactosidase. A mistura de reação constou de $750 \mathrm{~mL}$ de

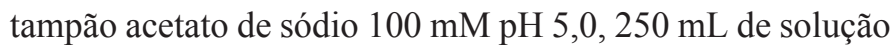
$2 \mathrm{mM}$ de r-NPGal e $10 \mathrm{~mL}$ do extrato enzimático. Os tubos contendo a solução foram mantidos em banho maria a $37^{\circ} \mathrm{C}$ por $15 \mathrm{~min}$, sendo interrompida a reação pela adição de 1,0 $\mathrm{mL}$ de solução de $0,5 \mathrm{M}$ de $\mathrm{Na}_{2} \mathrm{CO}_{3}$. Os valores de absorbância medidos no comprimento de onda de $410 \mathrm{~nm}$ foram transformados em mmoles de -nitrofenolato (-NP), utilizando uma curva padrão construída com 0-0,20 mmoles de -NP. A unidade de enzima foi definida como sendo a quantidade de proteína necessária para produzir um mmol de r-NP por minuto nas condições do ensaio.

Para a determinação do pH ótimo da enzima foram conduzidas reações em solução tampão com $\mathrm{pHs}$ variando de 4,0 a 8,0, utilizando-se tampões McIlvine (McIlvaine, 1921), mantendo-se as mesmas condições de ensaio descritas anteriormente.

Os ensaios de temperatura foram feitos em 20, 25, 30, $35,40,45,50,55$ e $60^{\circ} \mathrm{C}$, em banho-maria, utilizando-se 
tampão Mcllvaine pH 5,0.

A termoestabilidade foi testada pela pré-incubação da mistura enzima + tampão por vários tempos na temperatura de $50^{\circ} \mathrm{C}$ no $\mathrm{pH} 5,0$. Após a pré-incubação o substrato foi adicionado e o ensaio foi conduzido como já descrito.

Os efeitos de íons, agentes redutores e açúcares foram avaliados utilizando-se $200 \mathrm{~mL}$ de soluções $10 \mathrm{mM}$ de $\mathrm{MgCl}_{2}$, $\mathrm{CaCl}_{2}, \mathrm{KCl}, \mathrm{CuSO}_{4}, \mathrm{NaCl}$, sódio dodecil sulfato (SDS), betamercaptoetanol, lactose, D-galactose, D-glicose, sacarose, rafinose, melibiose, ácido etilenodiaminotetraacético (EDTA) e iodoacetamida. A mistura contendo tampão, enzima e efetor foi pré-incubada por $15 \mathrm{~min}$., a $40^{\circ} \mathrm{C}$ e, em seguida, foram acrescentados $250 \mathrm{~mL}$ de solução $2 \mathrm{mM}$ de -NPGal, sendo conduzido o restante do ensaio da mesma maneira já descrita. $\mathrm{O}$ ensaio controle utilizou apenas o substrato r-NPGal sem adição de nenhum efetor.

Os ensaios para determinação de $\mathrm{K}_{\mathrm{M}} \mathrm{e} \mathrm{V}_{\max }$ aparentes foram realizados com utilização de diferentes concentrações de -NPGal. As concentrações usadas foram 0,032, 0,064, $0,118,0,192,0,32,0,64,0,8,1,28$ e 1,6 mM. Os valores de $\mathrm{K}_{\mathrm{M}} \mathrm{e} \mathrm{V}_{\max }$ aparentes foram calculados por meio da curva de velocidade e pela equação do duplo recíproco (Lineweaver \& Burke, 1934). Foi utilizado o programa Curve Expert, versão 1.3 para Windows (Hyams, 1997).

A extração de proteínas solúveis foi realizada pelo método descrito por Alfenas et al. (1991), a qual consistiu em moer os embriões em tampão fosfato de sódio, $0,05 \mathrm{M} \mathrm{e} \mathrm{pH} \mathrm{7,0.} \mathrm{A}$ quantificação foi feita conforme descrito por Bradford (1976).

\section{RESULTADOS E DISCUSSÃO}

Verifica-se na Figura 1 a atividade da enzima alfagalactosidase durante o período de 120 horas de embebição. Há um nítido aumento da atividade no eixo embrionário durante todo o tempo de observação, mas em especial a partir de 48 horas, quando há aceleração da atividade, estabilizando-se a partir de 96 horas. Borges et al. (2001) observaram, em sementes dessa mesma espécie, quando submetidas a estresse hídrico, que a atividade se manifesta mais claramente em 120 horas de embebição, estando o fator, aparentemente, ligado ao nível de embebição, uma vez que no segundo caso a hidratação é mais lenta. Por outro lado, observa-se aumento lento da atividade nos cotilédones durante esse tempo, o que permite concluir que a mobilização de reservas ligadas a galactomanano ocorre primeiro no eixo embrionário, gerando substrato para a respiração e formação de estruturas de carbono para o crescimento do mesmo.

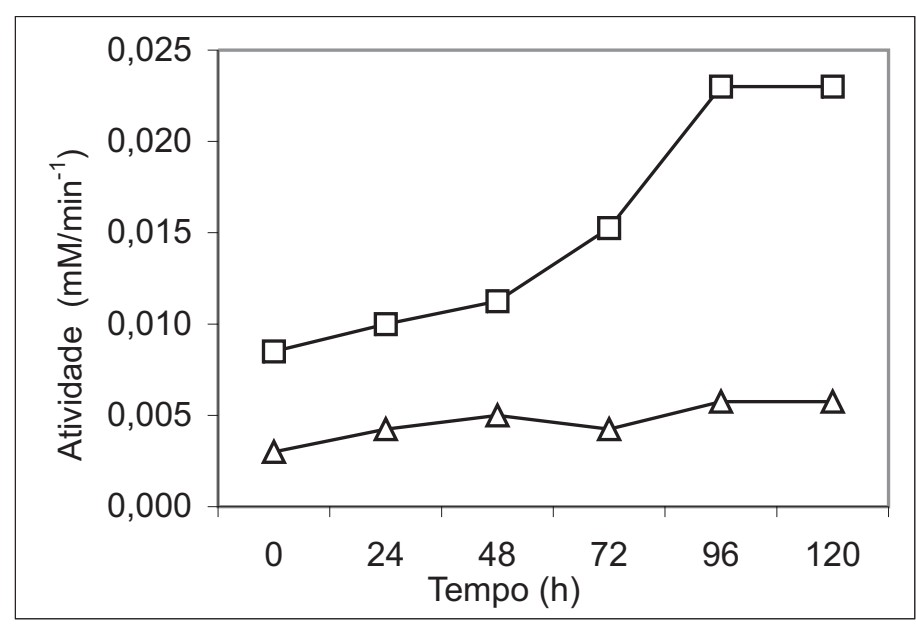

FIGURA1. Atividade das alfa-galactosidases do eixo embrionário $(\square)$ e dos cotilédones $(\Delta)$ de sementes de Platymiscium pubescens durante o período de embebição.

Os dados relativos à atividade da enzima em relação à variação do $\mathrm{pH}$ encontram-se na Figura 2. Percebe-se que a atividade das enzimas do eixo embrionário e dos cotilédones são maiores na faixa de $\mathrm{pH}$ entre 4,5 e 6,0, muito embora as diferenças nas atividades em função do $\mathrm{pH}$ para a alfagalactosidase do embrião sejam mais acentuadas. Trabalhando com sementes de soja, Viana (2002b) obteve valor máximo de atividade no $\mathrm{pH} 6,0$, muito embora os valores nos $\mathrm{pHs}$ 5,0 a 6,0 fossem bastante próximos. Guimarães (2001) trabalhando com sementes de soja identificaram a faixa de pH entre 5,0-5,5 como adequada. Dey (1981) encontrou

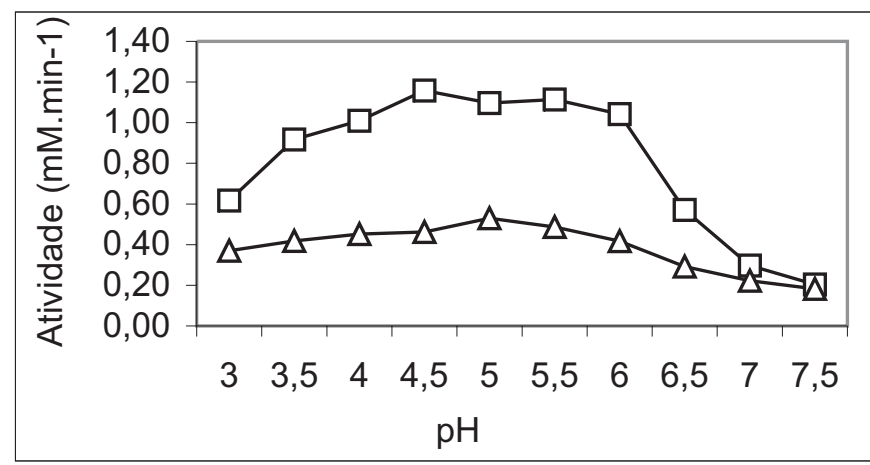

FIGURA2-Atividades das alfa-galactosidase do eixo embrionário $(\square)$ e dos cotilédones $(\Delta)$ de sementes de Platymiscium pubescens em diferentes pHs. 
valores ótimos de atividade de alfa-galactosidase em sementes de Castanea sativa em pHs 4,5 em uma fração e 6,0 em outra.

Observa-se na Figura 3 que as atividades das alfagalactosidases do embrião e dos cotilédones aumentam com o aumento da temperatura. Enquanto a temperatura ótima para a alfa-galactosidase do embrião se situa em $55^{\circ} \mathrm{C}$, a do cotilédone está na faixa $50-55^{\circ} \mathrm{C}$. Em ambos compartimentos, a atividade decresce na temperatura de $60^{\circ} \mathrm{C}$. Guimarães (2001)

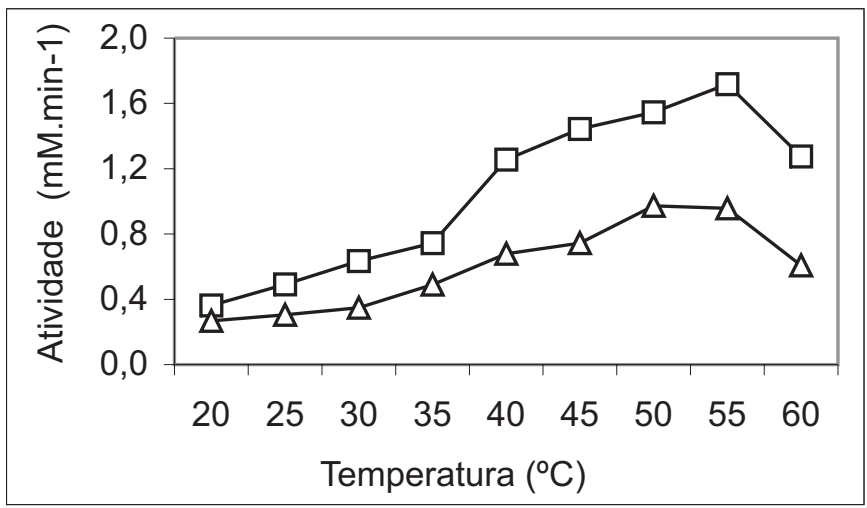

FIGURA3. Atividade das alfa-galactosidases do eixo embrionário $(\square)$ e dos cotilédones $(\triangle)$ de sementes de Platymiscium pubescens em diferentes temperaturas. e Viana (2002 a) obtiveram maiores atividades nas faixas 45 $50^{\circ} \mathrm{C}$ e $40-55^{\circ} \mathrm{C}$ respectivamente, para sementes de soja, variedades Doko e CAC-1.

Os resultados dos ensaios para determinar a meia vida das enzimas do eixo embrionário e dos cotilédones a $40^{\circ} \mathrm{C}$ (Figuras 4 e 5) foram ajustadas de acordo com a expressão não linear da variação da velocidade em função do tempo de pré-incubação. Não foi possível atingir a metade da atividade original mesmo após o tempo de 1.500 min de pré-incubação, o que mostra que a enzima apresentou alta termoestabilidade. Ensaio realizado por Viana (2002 a) com sementes de soja, na mesma temperatura, também não permitiu identificar a metade da atividade da mesma enzima no tempo de 780 minutos. Por outro lado, Guimarães (2001) determinou a meia vida da mesma enzima, em sementes de soja DOKO, na temperatura de $30^{\circ} \mathrm{C}$, em 253,95 min e 1.199 min para duas formas distintas da alfa-galactosidase.

Tem-se nas Figuras 6 e 7 as atividades relativas das enzimas provenientes do eixo embrionário e dos cotilédones, respectivamente, na presença de diversos íons, açúcares, detergentes, agentes redutores e outros. Verifica-se que os sais de cloretos de magnésio, de potássio, de cálcio e de sódio, sacarose, glicose, beta-mercaptoetanol, iodoacetamida, EDTA, lactose, maltose e rafinose, estimularam a atividade da enzima proveniente do embrião. A D-galactose teve efeito neutro, uma

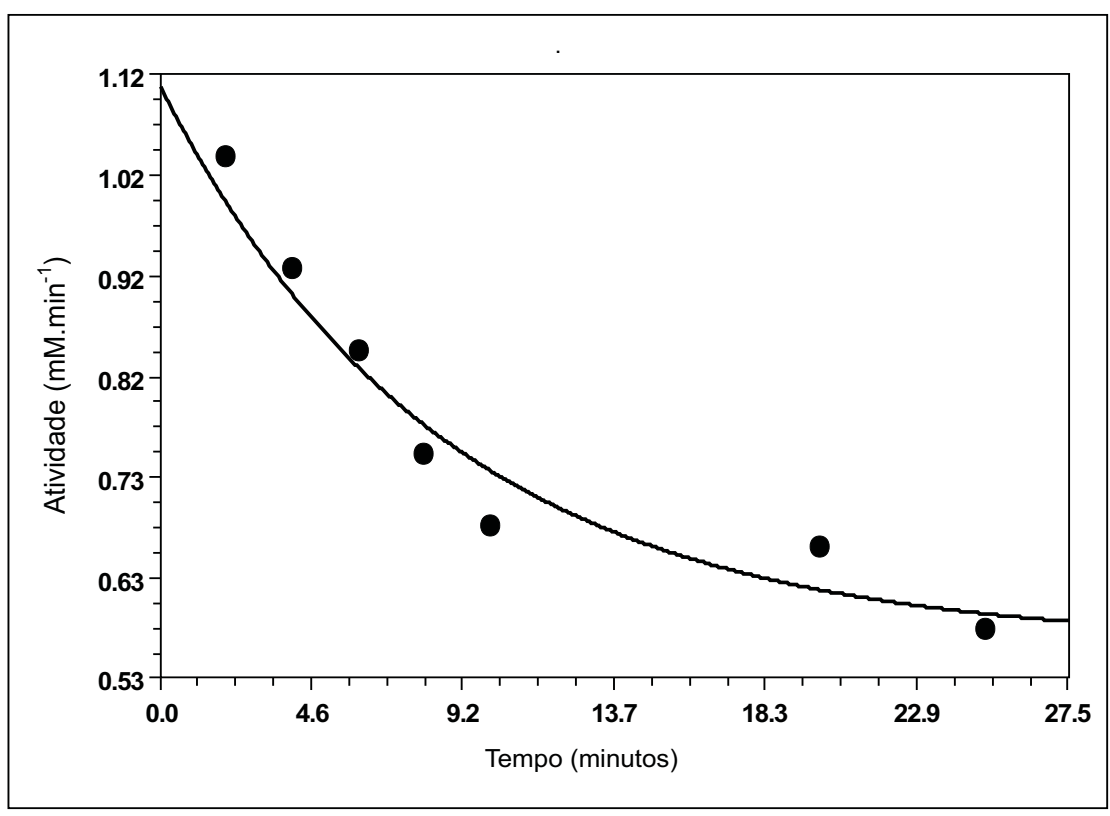

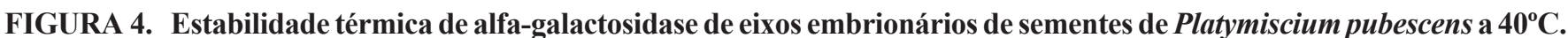

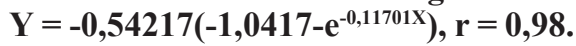




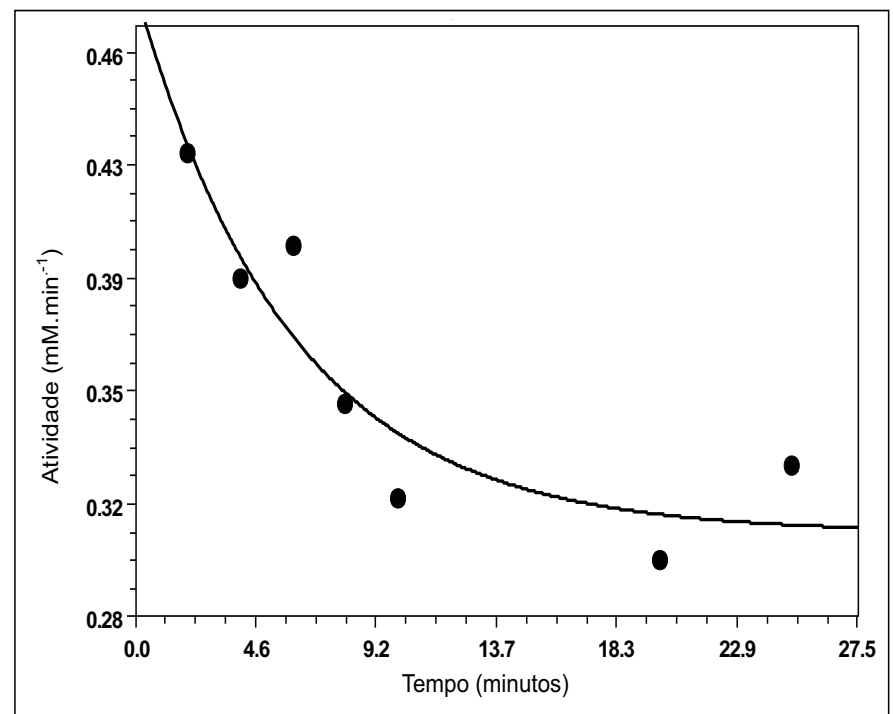

FIGURA 5. Estabilidade térmica de alfa-galactosidase de cotilédones de sementes de Platymiscium pubescens em temperatura de $40^{\circ} \mathrm{C}$. $\mathrm{Y}=\mathbf{- 0 , 1 7 2 4 1}\left(-1,79118-\mathrm{e}^{-0,16953 \mathrm{X}}\right), \mathrm{r}=\mathbf{0 , 9 6}$

vez que a sua atividade foi semelhante àquela observada quando o ensaio continha apenas o -NPGal. Observou-se efeito inibitório da melibiose, sulfato de cobre e do SDS, com efeito mais ativo nessa seqüência. Por outro lado, percebe-se que o comportamento foi modificado quando se trabalhou com extrato dos cotilédones, onde D-galactose, sulfato de cobre e SDS tiveram efeito neutro. O cloreto de cálcio teve efeito inibitório e situou-se em posição intermediária em relação ao outro grupo, cujo efeito inibitório foi maior, constituído de sacarose, cloreto de magnésio, D-glicose, cloreto de sódio, lactose, beta-mercaptoetanol, maltose e rafinose. Finalmente, o último grupo foi constituído por cloreto de potássio, melibiose, EDTA e iodoacetamida, que apresentou efeito inibitório maior do que os demais. Percebe-se, assim, que há diferença entre os extratos enzimáticos provenientes do eixo embrionário e dos cotilédones. Trabalho realizado por Oliveira et al. (2002) mostraram que o sulfato de cobre foi o agente que promoveu maior inibição da alfa-galactosidase de sementes de Platymiscium pubescens, seguido do SDS. O iodoacetamida e o beta-mercaptoetanol tiveram efeito estimulante, semelhante ao obtido com extratos de eixo embrionário, mas diferindo dos resultados obtidos com extrato dos cotilédones. O sulfato de cobre provocou efeito distinto para as enzimas estudadas, pois enquanto para o eixo embrionário houve efeito inibitório, para os cotilédones não houve maiores alterações.

Os efeitos das concentrações do substrato -NPGal na velocidade de hidrólise do mesmo pelos extratos de alfagalactosidase de eixo embrionário e de cotilédones foram determinados conforme mostrado nas Figuras 8, 9, 10 e 11, respectivamente.

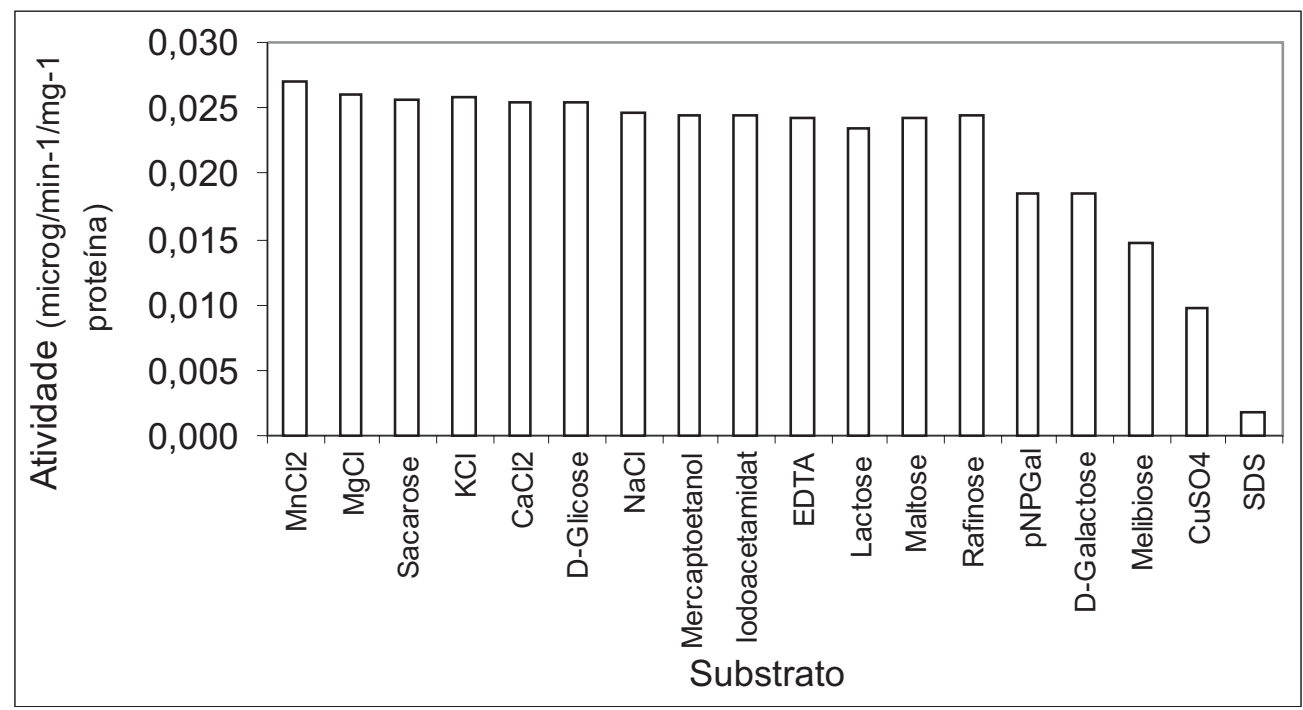

FIGURA 6. Atividade específica de alfa-galactosidase de eixos embrionários de sementes de Platymiscium pubescens em relação a íons, agentes redutores e açúcares. 


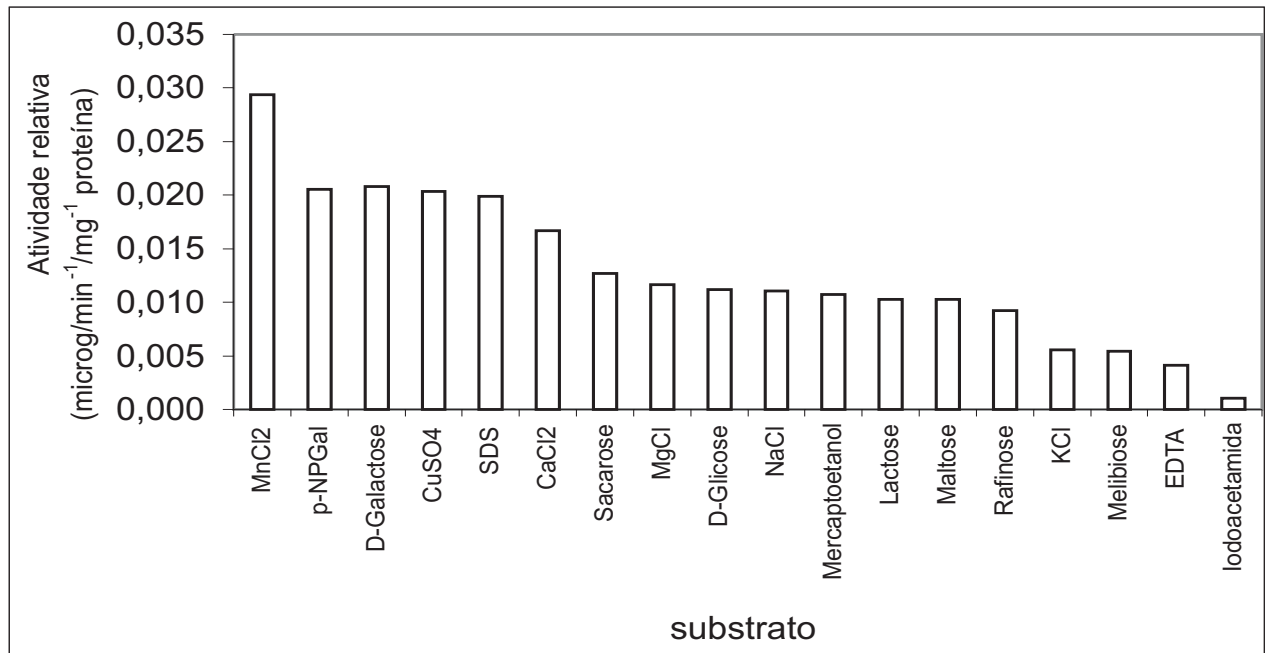

FIGURA 7. Atividade específica de alfa-galactosidase de cotilédone de sementes de Platymiscium pubescens em relação a íons, agentes redutores e açúcares.

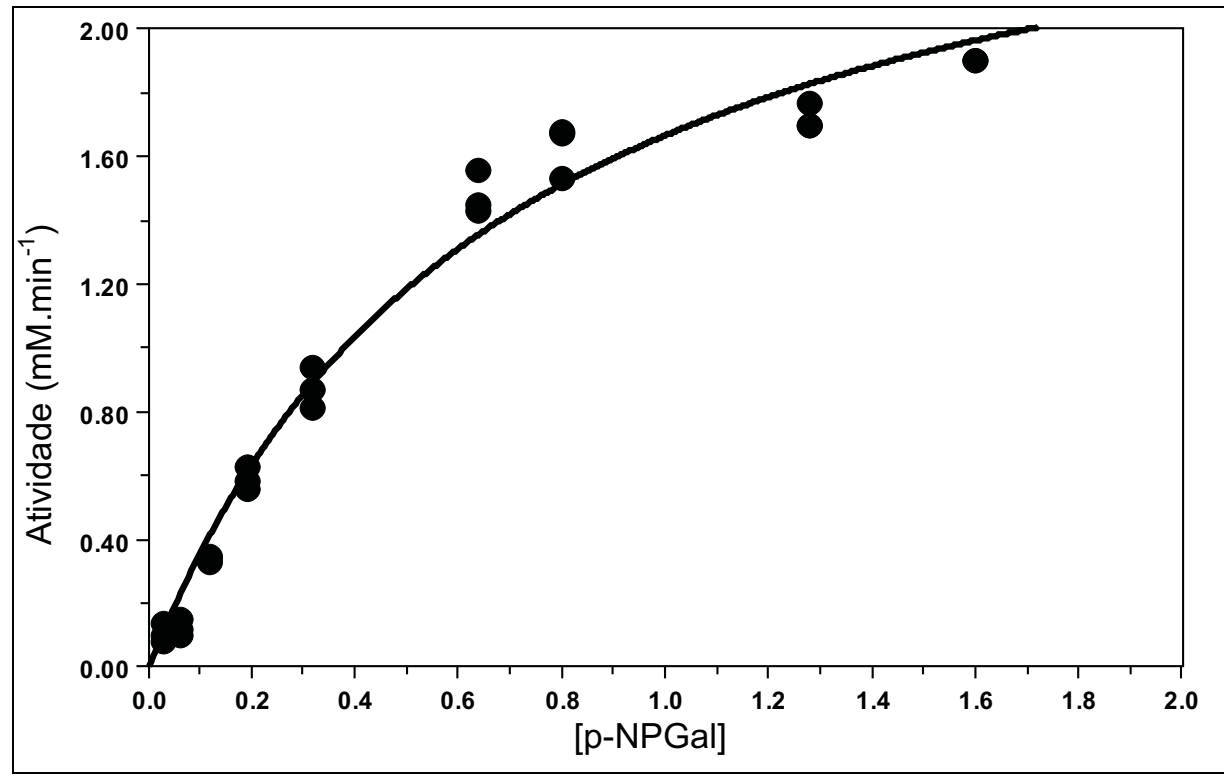

FIGURA 8. Gráfico de Michaelis-Menten para hidrólise de p-NPGal pela alfa-galactosidase em embrião de sementes de Platymiscium pubescens. Os valores de $\mathrm{K}_{\mathrm{M}} \mathrm{e} \mathrm{V}_{\max }$ aparentes obtidos foram $3,37 \mathrm{mM}$ e 1,0mM.min ${ }^{-1}$ respectivamente. 


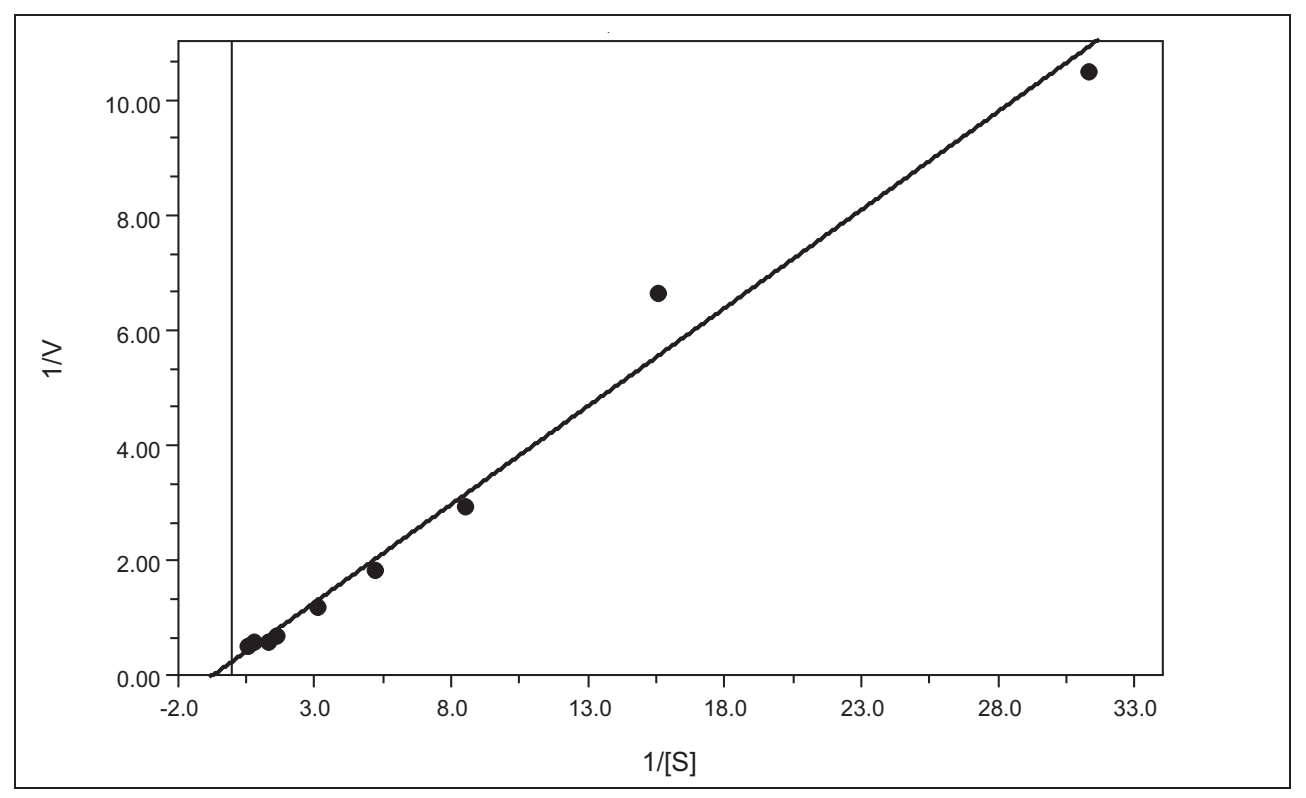

FIGURA 9. Gráfico duplo recíproco de alfa-galactosidase em eixo embrionário de sementes de Platymiscium pubescens.

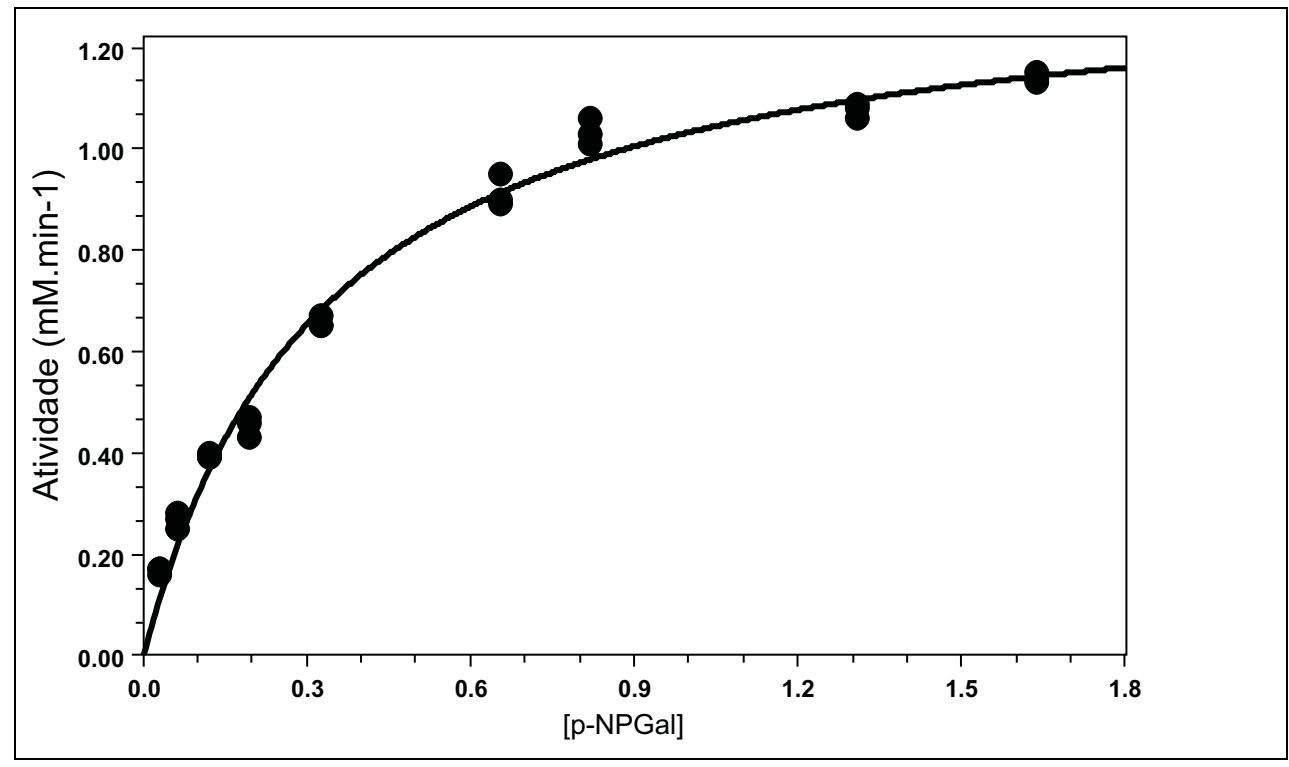

FIGURA 10. Gráfico de Michaelis-Menten para hidrólise de $\rho$-NPGal pela alfa-galactosidase de cotilédones de sementes de Platymiscium pubescens. Os valores de $\mathrm{K}_{\mathrm{M}}$ e $\mathrm{V}_{\max }$ aparentes obtidos foram $0,26 \mathrm{mM}$ e 1,28 mM.min ${ }^{-1}$, respectivamente.

Os valores de $\mathrm{K}_{\mathrm{M}}$ para o eixo embrionário e para o cotilédone foram 3,37 e $0,26 \mathrm{mM}$, respectivamente, mostrando que as enzimas nos dois compartimentos das sementes são, provavelmente, enzimas distintas. Os valores encontrados para alfa-galactosidases foram $0,99 \mathrm{mM}$ em sementes de Pterogine nitens (Reis, 2003), 0,30 Mm em sementes de Glycine max vr. CAC-1 (Viana, 2002) e 1,57 mM para sementes de Tachigalia multijuga (Fialho et al., 2002b). Oliveira et al. (2002) obteve valores de 0,48 $\mathrm{mM}$ e 0,65 Mm nas duas formas de alfa-galactosidase encontradas na purificação de extratos de sementes de Platymiscium pubescens. 


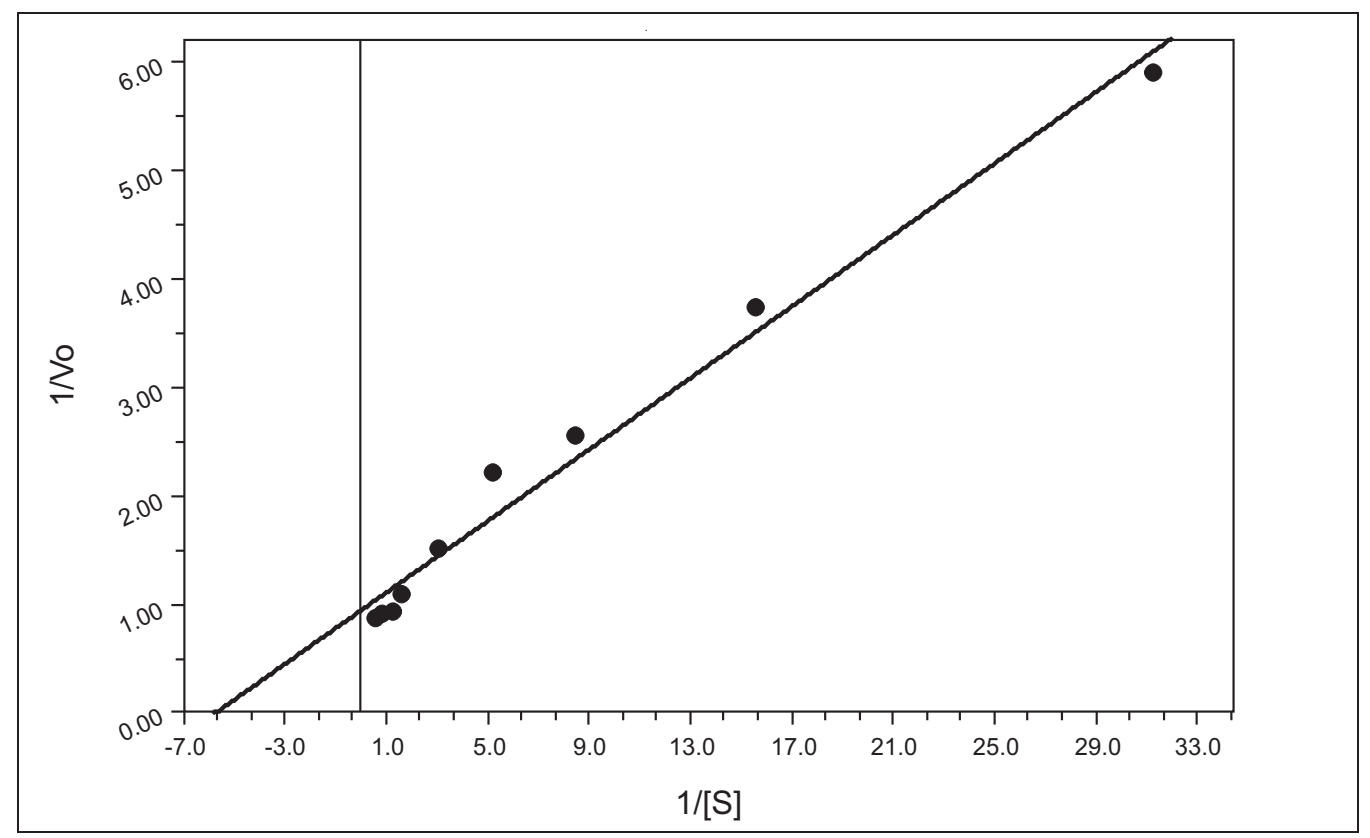

FIGURA 11 - Gráfico duplo recíproco de alfa-galactosidase em cotilédones de sementes de Platymiscium pubescens.

\section{CONSLUSÕES}

A alfa-galactosidase está presente em sementes secas e aumentam a atividade no eixo embrionário durante a embebição.

A atividade da alfa-galactosidase é máxima a $55^{\circ} \mathrm{C}$ no eixo embrionário e cotilédones. A atividade da enzima é maior na faixa de $\mathrm{pH}$ de 4,5 a 6,0.

A estabilidade térmica da alfa-galactosidase a $40^{\circ} \mathrm{C}$ está além de $1.500 \mathrm{~min}$.

As alfa-galactosidases do eixo embrionário e dos cotilédones têm sensibilidades diferentes a presença de açúcares, íons e agentes redutores.

As alfa-galactosidases do eixo embrionário e dos cotilédones são diferentes na afinidade em relação ao r-NPGal, pois os valores de $\mathrm{K}_{\mathrm{M}}$ calculados para esse substrato são diferentes.

\section{REFERÊNCIAS}

ALFENAS, A.C.; PETERS, I.; BRUNE, W.; PASSADOR, G.C. Eletroforese de proteínas e isoenzimas de fungos e essências florestais. Viçosa: SIF, 1991. 242p.

BOM, I.; WASSENAAR, D.; BOOT, J. Hybrid affinity chromatography of alpha-galactosidase from Verbascum thapsus L. Journal of Chromat., Oxford, v.808, n.1, p.133-139, 1998.

BORGES, E.E.L.; PEREZ, S.C.G.A.; BORGES, R.C.G.; REZENDE, S.T. Comportamento fisiológico de sementes osmocondicionadas de Platymiscium pubescens (tamboril-da-mata). Revista Árvore, Viçosa, v.26, n.5, p.603-613, 2002.

BRADFORD, M.M. A rapid and sensitive method for the quantification of microgram quantities for protein utilizing the principle of protein-dye binding. Analytical Biochemistry, Maryland, v.72, p.248-254, 1976.

BULPIN, P.V.; GIDLEY, M.J.; JEFFLOAT, R.; UNDERWOOD, D.R. Development of a biotechnologycal process for the modification of galactomanann polymers with plant alpha-galactosidase. Carbon Polymers, v.12, p.155-168, 1990.

CAMACHO, L.; SIERRA, C.; CAMPOS, R.; GUZMÁN, E.; MARCUS, E. Nutritional changes caused by germination of staple chilean legumes. Archivos Latiamericano de Nutricion, Caracas, v.42, n.3, p.283-290, 1992.

CHEN, S.H.; LIN-CHU, M. The conversion of group B red blood cells into group B by an alpha-galactosidase from tarol (Colocasia esculenta). Carbohidrate Research, Oxford, v.217, p.191-200, 1991.

CRUZ, R.; BATISTELA, J.C.; WOSLACKI, G. Microbial agalactosidase for soy milk processing. Journal of Food Science, Chicago, v.46, n.4, p.1126-1200, 1981.

DEY, P.M. Alpha-galactosidase from sweet chestnut seeds. Phytochemistry, Oxford, v.20, p.1493-1496, 1981.

FEURTADO, J.A.; BANIK, M.; BEWLEY, J.D. The cloning and characterization of alpha-galactosidase present during and following germination of tomato (Lycopersicon esculentum Mill.) seed. Journal of Experimental. Botany, Oxford, v.52, n.359, p.12391249, 2001.

FIALHO, L.S.; BORGES, E.E.L.; GUIMARÃES, V.M.; OLIVEIRA, M.G.A.; MOREIRA, M.A.; REZENDE, S.T. Prospecção e estudo 
de alpha-galactosidase em sementes de leguminosas. In: SIMPÓSIO DE INICIAÇÃO CIENTÍFICA, 11., 2002, Viçosa. Anais... Viçosa: UFV, 2002a, p.250.

FIALHO, L.S.; GUIMARÃES, V.M.; BORGES, E.E.L.; JOSE, I.C:; OLIVEIRA, M.G.A.; REZENDE, S.T. Partial purification and characterization of á-galactosidase from Tachigalia multijuga seeds. In: REUNIÃO ANUAL DA SOCIEDADE BRASILEIRA BIOQUÍMICA E BIOLOGIA MOLECULAR, 31., 2002,Caxambu. Anais... Caxambu: (SBBQ), 2002b, p.124

GUIMARÃES, V.M.; REZENDE, S.T.; MOREIRA, M.A.; BARROS, E.G.; FELIX, C.R. Characterization of alpha-galactosidase from germinating soybean seed and their use for hydrolisis of oligossacharides. Phytochemistry, Oxford, v.58, p.67-73, 2001.

HYAMS, D. Curve expert 1.3: a comprehensive curve fitting system for Windows. Copyright ${ }^{(\mathrm{C})} .1997$.

LINEWEAVER, H.; BURKE, D. The determination of enzyme dissociation constants. Journal American Chemistry Socciety, Washington, v.56, p.658-666, 1934.

McILVAINE, T.C. A buffer solution for colorimetric comparasions. Journal of Biological Chemistry, Bethesda, v.49, p.185-186, 1921.
OLIVEIRA, G.; GUIMARÃES, V.M.; BORGES, E.E.L.; OLIVEIRA, M.G.A.; REZENDE, S.T. Purification and characterization of alfa galactosidases from germinating seeds of Platymiscium pubescens. In: REUNIÃO ANUAL DA SOCIEDADE BRASILEIRA BIOQUÍMICA E BIOLOGIA MOLECULAR, 31., 2002, Caxambu. Anais... Caxambu: (SBBQ), 2002b, p.124

VIANA, S.F. Caracterização de alfa galactosidase de soja para hidrólise de oligossacarídeos de rafinose. 2002. 65f. Dissertação (Mestrado em Fitotecnia) Universidade Federal de Viçosa, Viçosa, 2002.

VIANA, S.F.; GUIMARÃES, V.M.; MOREIRA, M.A.; OLIVEIRA, M.G.A.; COSTA, N.M.B.; de REZENDE, S.T. Reduction of raffinose oligosaccharides in soymilk by alpha-galactosidase from germinating soymilk seeds. In: REUNIÃO ANUAL DA SOCIEDADE BRASILEIRA BIOQUÍMICA E BIOLOGIA MOLECULAR, 31., 2002, Caxambu. Anais... Caxambu: (SBBQ), 2002b, p.95

ZEILINGER, S.; KRISTUFEK, D.; ARISSAN-ATAC, I.; RODITS, R.; KUBICEK, C.P. Condition of formation, purification, and characterization of an alpha-galactosidase of Trichoderma reesei RUTC-30. Applied Environmental Microbiology, Washington, v.59, n.5, p.1347-1353, 1993. 